\title{
Analyzing French and Italian iPhone 4S Mobile Cloud customer satisfaction presented by Organizational Sustainability Modeling
}

\author{
Victor Chang, \\ School of Computing, Creative Technologies and Engineering, \\ Leeds Metropolitan University, Leeds, UK. \\ Electronics and Computer Science, University of Southampton, Southampton, UK \\ V.I.Chang@leedsmet.ac.uk
}

\begin{abstract}
This book chapter explains the use of Organizational Sustainability Modeling (OSM), a model to evaluate the status of risk and return for Cloud Computing including Mobile Cloud, where the customer satisfaction rate is an important indicator. We describe how to use OSM to collect and analyze French and Italian 2011 data, in which the iPhone $4 S$ Cloud service in these two countries is used as the representation for Mobile Cloud industry. OSM data analysis shows that both French and Italian data have declined customer satisfaction, being affected by the economic downturn. There are medium-high uncontrolled risks and good data consistencies in both countries. The use of $3 D$ Visualization helps further data analysis and interpretation. Comparisons between French and Italian data are presented, and rationale for their similarities and differences are explained in details. Additionally, OSM and other similar methods are compared. Due to the capabilities to support both quantitative and qualitative approaches with support from real case studies, OSM is a better method to analyze customer satisfaction in Mobile Cloud.
\end{abstract}

\section{Introduction}

Since the development of Cloud Computing in the industry, more organizations have adopted Cloud Computing for a variety of projects and services, including backup, experiments, web hosting, word processing, email, mobile services and highly specialized applications (Dinh et al., 2011; Marston et al., 2011; Chang et al., 2013 a). There are different types of reasons of adopting Cloud Computing. Some foresee as business opportunities; some regard Cloud Computing as a platform to integrate their IT infrastructure; some use Cloud as a resource to develop applications which can be shared and reused. All the reasons mentioned above are the drive for organizations to adopt Cloud Computing (Rochwerger et al., 2009; Marston et al., 2011). In all different types of Cloud adoption, there are industries that have more competitions due to the fast-growing area in the global market and the user community. One such an area is Mobile Cloud, which is a fast-growing area due to the rise of smart phones, better infrastructures (such as 4G), better services and better applications (app) available to a large number of users (Dinh et al., 2011; Qiang et al, 2012). Similarly, price wars between different smart phones, between different mobile service carriers, between different mobile app and between different have become more intense. For example, an iPhone $4 \mathrm{~S}$ phone $8 \mathrm{~GB}$ can be purchased with $£ 20$ per month for a two-year contract in 2014. In 2011, this would 
have cost $£ 45$ per month plus the additional fees to own the smart phones. Some researchers argue that the drop in price may not guarantee in maintaining a good quality of service. However, the $4 \mathrm{G}$ network has been more established and more mature than in 2011, some users do not feel there is a huge difference between their service quality in 2011 and 2014. The Mobile phone and service industry is one of the competitive areas. However, there is insufficient amount of quantitative research investigating the Mobile Cloud service industry such as customer satisfaction, profitability or the business models. Although there are qualitative research projects in this area, they do not fully address the requirements and challenges in Mobile Cloud industry. We argue that concrete quantitative data and evidences must be fully demonstrated in support of any existing hypotheses. Additionally, innovative technique of analyzing the user data is important to understand the consumer behavior, since users may change their habits and behaviors in shorter periods of time than other industries (Idongesit and Skouby, 2014). For example, some apps could be popular a few years ago and could face the challenge of organizational survival if they did not update and evolve their services. One example is the Chinese version of Farmville, which had millions of users in 2009. They did not change their games and services for four years. They experienced a large number of declines in users due to other apps available, which could be free and could work on all different mobile operating systems. In 2013, the company filed up a statement of bankruptcy.

Customer satisfaction is an important indicator for the service industry, since it offers evaluations to the services on offer and it provides valuable information for investors for them to decide the scale and amount of investment. If a company does not perform well in their customer satisfaction, there are a few consequences. First, customers may leave and join other service providers. Second, if there is a decline, depending on the scale of decline in maintaining existing number of customers, the company may experience financial difficulties due to reduced revenues and fewer investors willing to put in more fund. There are studies about direct relationship between maintaining customer satisfaction and profitability. Both Heskett and Schlesinger (1994) and Hallowell (1994) demonstrate the direct positive relationship between the improved customer satisfaction and profitability. Several statistical data and empirical evidence presented by both groups of researchers assert that the loyal customers contribute to the profitability of the service industry. Although the short-term relationship cannot be easily identified, maintaining high customer satisfaction and profitability are related in the long-term. If a company struggles to maintain an acceptable level of customer satisfaction, they may experience a decline of existing customers with reduced revenue and poor corporate reputation. This will not help the company to be profitable in the long term, since they may lose out to competitors with similar services.

Cloud computing promises to revolutionize the provision of major computing services, bringing with it benefits for all types of users. These benefits vary from simplified administration for systems programmers to ready access to massive processing power on demand for desktop users. However, to gain the full benefits, a full commitment to Cloud computing is necessary and this brings with it a requirement for users to revise business processes and attitudes to computing services in addition to the 
immediately obvious systems changes (Barry, 2012). Therefore evaluation of a Cloud computing project must consider the balance of benefits and risks to the organization in the context of its environment in addition to technical considerations.

A number of methods that can analyze the customer satisfaction in the fast-growing Mobile Cloud service have been investigated. We realize that there is no any quantitative method addressing this issue. Methods such as Weinhart et al (2009) and Klem et al (2009) are qualitative - they do not even present papers specific to Mobile Cloud industry. One of the recognized methods available to analyze investments is Capital Asset Price Modeling (CAPM) which is able classify risks into uncontrolled or managed types (Sharpe, 1990). CAPM takes proper account the risks associated with an investment and the context in which it is made. However Cloud computing projects present some particular challenges which are not well addressed by CAPM which has been developed as a generic technique for evaluating investments and business projects.

\section{Models for analyzing risk and return status for Mobile Service}

This section describes the method of analyzing risk and return. Return may mean profitability, customer satisfaction, or any goals that have to be accomplished. Risk may mean the uncontrolled and controlled risk. This classification is important as confirmed by Sharpe in this Nobel-winning model, Capital Asset Pricing Model (CAPM) (Sharpe, 1990). The supporting rationale is as follows. Each Cloud service needs to identify what risks are, classify whether they can be managed. Each Cloud service will expect some forms of unexpected risk, which include impact due to financial crisis, natural disaster and accidents (car, fire, flood and so). These events cannot be managed with the human intervention, although actions we provide can reduce the impacts damaged by those events. Hence, all Cloud Computing services including Mobile services should contain the status of return and risk (controlled and uncontrolled).

\subsection{An overview in choosing suitable models}

This section describes some of the suitable models for calculating risk and return. Monte Carlo simulations (MCS) have been widely used in financial analysis and computation. Longstaff et al demonstrate the use of Least Squared Method (LSM) to enable large-scaled computations to be completed in a short period of time (seconds). Chang et al (2011 a) follow their steps to make improved prototype and demonstrate the use of MCS for undertaking large-scaled simulations on the private and public clouds, and they have contributions for developing financial analysis. However, Monte Carlo simulations require specific business cases of investment. Input key values should be determined and verified. With Cloud Computing, the use of public cloud does not require a high capital input, since it can cost as low as one dollar to buy a virtual machine as a service for computation. Monte Carlo simulation should be used for predicting the put and call prices of an investment. Additionally, MCS regards risk as a single entity (Teunis and Havelaar, 2000; Jampani et al., 2008) and does not have a definition to calculate the uncontrolled risk. 
Black Scholes Models (BSM) have been used in financial derivatives and computation (Eberlein and Keller, 1995; Carr and Madan, 1999). This includes the use of Cloud Computing to calculate financial derivatives in both numerical forms and visualization (Chang et al., 2011 a; Chang 2014 a; 2014 b). Sharma et al (2002) demonstrate the use of their improved BSM for Cloud Computing and they focus on the service providers' points of view. However, Cloud Computing is not limited to service providers but also a variety of organizations and users, and also in public clouds and community clouds, which may not even follow their recommendation. Additionally, BSM does not classify risks into uncontrolled and uncontrolled types.

Binomial Trees can be used to investigate the dependency of different factors contributing to the success of managing Cloud Computing projects. However, the model assumes that all the factors are dependent on each other, since the value of the probability can indicate the dependency relationship. For example, the model determines two major factors, one contributing to $30 \%$ and the other $70 \%$. In the second main factor, it then divides into four other factors. The last factor (in the second main factor) then contributes to $10 \%$, and the probability is thus 0.1 . However, some risks are independent of each other. For example, if one Mobile service is managing all controlled risks under $2 \%$ (all stocks are available; all services are up-and-running; disruptions of services can be resumed within 2 hours), when the country has experienced flood and the town was in a flood situation. Then there is no way to prevent a flood from being happening to cause the damage. Similarly, the probability of having a flood is not dependent on the way that the business is managed. Thus, risks are not necessarily dependent but they can be independent. The better approach is to divide whether risks are uncontrolled or controlled before using Binomial Tree or dividing them into different percentages of probabilities.

\subsection{Capital Asset Pricing Model}

A key feature of Capital Asset Pricing Model (CAPM) is that it divides risks associated with an investment into two categories: those which can be controlled and managed, and those which cannot. For example, when considering risk in a stock market portfolio, risks associated with the relative fortunes of individual companies arising from the foresight and proficiency of their management may be managed and ameliorated by spreading an investment across a variety of different companies. However, a general trading downturn is an inherent characteristic of this type of investment which cannot be avoided. There are researchers demonstrating the use of CAPM is suitable for Cloud Computing (Gentzoglanis, 2011). CAPM can be used for Cloud Computing except the improvement on the handling of big data and the requirements for adaptation for Cloud Computing (Chang, 2013).

CAPM can analyze uncontrolled and managed risk associated with the status of return. Comparing with models described in Section 2 and 2.1, CAPM apparently appears to be more suitable. Although CAPM is a generic model suitable for any disciplines, it has two limitations. First, it struggles to handle large datasets and its focus on econometrics. At the time that CAPM was being developed, the extremely large digital datasets which are common today did not exist so there was no need for CAPM in its 
original from to be able to handle thousands of datasets at once. Thus, CAPM does not address how to handle large datasets. When the volume of data being generated by organizations adopting new technologies growing, the capacity to handle thousands of datasets is important for data-based research (Hey et al., 2009). This inability of basic CAPM models to handle data-intensive cases leads to longer computational times. This explains why it is necessary to handle big datasets due to the rapid data growth experienced by many organizations. To tackle this problem, researchers have developed revised own models such as "International CAPM" which can compute a large number of financial datasets at once (Hamelink, 2000).

Second, CAPM is focused on econometrics and calculation of investment portfolio risk and return analysis (Sharpe, 1990; Hull, 2009). It can be used as a generic solution but a more tailored approach is desirable for computing in which key input values correspond to technical rather than financial terms such as return on the market and riskfree rate in the market. For use in IT system adoption scenarios, CAPM needs to be redesigned. The required attributes and key performance indicators should be revised to focus on measuring expected and actual returns while keeping risk-control rate low. By doing this, the revised model will become a better fit to the task of risk analyses for organizations adopting large systems such as Cloud Computing.

\section{The overview of a proposed model, Organizational Sustainability Modeling (OSM)}

As discussed in Section 2 and 2.1, the development of a new or improved model is necessary. While reviewing suitability of the models described earlier, CAPM is the one for further development. The main reasons are first, it is a generic model for analyzing risk and return. Second, it has the classification of uncontrolled and controlled risks. The areas for improvement include:

- Making the revised model suitable for evaluating Cloud Computing adoption

- Modifying the model so that it can process the thousands of datasets or millions of datapoints at once without extra work

The proposed model is called Organizational Sustainability Modeling (OSM), which help organizations analyze their risk and return status. It has several case studies to support its validity. These include:

- Vodafone and Apple: Analyze the profitability and risk. There was an actual $21-26 \%$ gain in the profitability after adopting Mobile /Cloud services.

- SAP: The use of SAP help small and medium enterprises (SMEs) to manage their risks within $1 \%$ and help SME to withstand the impact due to financial crisis.

- University of Southampton: The use of OSM helps analyzing the cost-saving of up to $22 \%$ due to the use of green Cloud Computing.

OSM revises and improves CAPM to assess risk and return analysis for organizations adopting large computer systems, such as the adoption of Cloud. The objective of OSM is 
to provide a systematic approach to help managers understand the status of risk and return of Cloud Computing projects and services.

\subsection{Details about Organizational Sustainability Modeling (OSM)}

Based on the original CAPM formula, OSM formula is

$e=\mathrm{r}_{c}+\beta\left(a-\mathrm{r}_{c}\right)$

Where:

$\mathrm{a}$ is the actual return (or performance) of a large computing systems project.

$\mathrm{e}$ is the expected return (or performance) of a large computing systems project.

$r_{c}$ is the risk-control rate, the rate of manageable risk.

$\beta$ is the beta value which represents a measure of uncontrolled risk.

The challenge is to calculate beta which determines the uncontrolled risk value, because it is an implicit value making it difficult to quantify. Beta values can be calculated for each dataset from the expected return, the actual return and risk-control rate. One approach would be to collect all beta values and calculate the mean value. Another approach for calculating beta is to perform linear regression, where the gradient of the slope is the value for beta [16]. Beta can be calculated by rearranging equation (1), giving

$$
\beta=\frac{\mathrm{e}-\mathrm{r}_{c}}{\mathrm{a}-\mathrm{r}_{c}}
$$

Where $\mathrm{a}$ is the actual return of a large computing systems project, $\mathrm{r}_{\mathrm{c}}$ is the risk-control rate, $\mathrm{e}$ is the expected return, and $\beta$ is the beta value representing a measure of uncontrolled risk as before.

Given a number of datasets, the value for beta $(\beta)$ is given by the gradient of a line through the datapoints. As with CAPM, OSM uses linear regression to compute a line of best fit. Ordinary Least Squares (OLS), as part of the OSM, is used to minimize the sum of squared vertical distances between the observed responses in the dataset and the line is the method used.

\subsection{OSM datasets processing}

This section describes how to proceed with OSM dataset processing. Chang (2014) explains how to use OSM to measure popularity of German iPhone 4S users in their evaluations of mobile services. In other words, OSM can be used to analyze similar cases for customer satisfaction measurement in using Mobile Cloud services.

Metrics collection can be undertaken by system automation on a regular basis, by surveys which need to be completed by a large sample size. Hundreds and thousands of datasets can be collected in this way while running experiments or conducting surveys 
over a period of time. This will ensure a large sample size for modeling but a numerous datasets makes analysis more complex and time-consuming (Huson et al., 2007).

The size of the data that OSM can handle is as follows. Each dataset contains up to 2,000 rows and 255 fields of records, which is then equivalent to 510,000 datapoints. There are then 500 datasets involved, which becomes $500 \times 510,000=255,000,000$ datapoints for analysis, which is considered a big data analysis that data processing is completed within seconds to calculate key outputs for businesses. Chang et al (2011 b; 2011 c) explain details about how to process data and the algorithms involved with data processing.

\subsection{OSM outputs}

As explained by Chang et al (2011 b, 2011 c) and Chang (2014 c, 2014 d), the OSM outputs are explained as follows.

- Beta $(\beta)$, a measure of uncontrolled risk that may affect the project.

- Standard Error of the mean: the range of the mean of the experimental results. Smaller standard errors imply more accurate and representative results.

- Durbin-Watson [18, 19], a test to detect autocorrelation (a relationship between values separated from each other by a given time lag) in the residuals of a regression analysis. The value should be greater than 1 . The value for $\operatorname{Pr}>\mathrm{DW}$ corresponds to the negative autocorrelation test (residuals eventually wither off) and is in favored by OSM. The value of $\mathrm{Pr}>$ DW should ideally get as close as to 1 to reflect the accuracy of the OSM regression. The difference between 1 and $\mathrm{Pr}$ $>$ DW can work out the p-value for the OSM analysis.

- Mean Square Error (MSE) is an estimator to quantify the difference between estimated and actual values. A low MSE value means there is a high correlation between actual and expected return values.

- R-squared value: It is a value to test how fit the regression is. However, it is equivalent to the term "R-squared value for firm" used in econometrics to describe the percentage of risks in proportion to the external or internal organizations or factors (Teoh et al., 2006; Damodaran, 2008; Lee et al., 2009). For example, if an organization has an R-squared value $(99.99 \%$ C.I) of 0.6 this means $60 \%$ of risks are from external bodies or the market, and $40 \%$ of risks come from the organization such as poor adoption decision, overspending, poor selection of equipment (resulting in accidents) and so on. Adoption of a large computer system also introduces risks and the R-squared value provides a good indication for the percentage and sources of beta risks.

\subsection{Supporting case studies}

There are several models proposed by Cloud Computing researchers. First, Weinhardt et al (2009) propose a framework for Cloud Computing and address the relationship between different levels of services. Their proposal can be used as a generic model for 
Cloud adoption. Klem et al (2009) propose their framework for Cloud Computing and explain that their approach can be adopted. Third, Sultan (2010) addresses the effectiveness of Cloud Computing for education and consolidates his conceptual ideas. However, all these papers do not have any real-life case studies to support their point of view, except Sultan (2014) that shows a case study to support. However, that is not a case study of fully using his recommendation and making positive impact with quantitative analysis.

The original concepts proposed by Weinhardt et al (2009), Klem et al (2009) and Sultan (2010) proposals lack of the support from real-life case studies and demonstrations. We defend that any proposed models or frameworks should have the support from real-life case studies and demonstrations, or they are in weak positions for organizational adoption. Our OSM model has case studies used in different domains and applications of the user adoption. In this paper, we demonstrate that the use of OSM to analyze French and Italian data of user satisfaction of using iPhone 4S Mobile Cloud services. We interpret the outputs from OSM analysis which can offer useful information for the stakeholders and decision-makers.

\section{French and Italian Case Studies: Analyzing the rate of customer satisfaction of iPhone 4S Mobile Service in France and Italy}

This section describes the case study in details, which presents how OSM is used to help analyze the rate of customer satisfaction of using iPhone 4S Mobile Service in France. Current literature has emphasized in the system design, development and deployment examples (Ganti et al., 2011 a; Rimal et al., 2011). There are few literature about the surveys focusing on the customers and their rating of satisfaction towards using Mobile Cloud services. It is crucial for businesses to understand consumer behaviors and preferences for mobile products and services. In order to define what to measure, propose how to measure and analyze data, a systematic method is required. OSM is the method to systematically compute all these data and explain the interpretations of these data, in the form of statistical modeling. Reporting the status of risk and return of such Cloud adoption is important, since it can provide stakeholders an overview about their service rating, risk monitoring and analysis about whether their strategies of offering Cloud services have met their expected targets. In this way, the businesses can be more adaptable to the fast-paced requirement changes for Cloud Computing, particularly Mobile Cloud, which is a fast-growing area.

\subsection{Motivation for using iPhone 4S, a representation of Mobile Cloud and a hypothesis}

Chang et al (2011 c) presented their Vodafone/Apple case study on Mobile Cloud and it had an overall coverage of iPhone and iPad models. The generalization provides useful recommendation for potential and current investors (Chang et al., $2013 \mathrm{~b}$ ). Based on our knowledge from investors' requirements, they feel analysis will be more useful if it can be focused on each specific model. This may include iPhone $4 \mathrm{~S}$ model alone and its 
computational analysis about its business performance that focuses on status of return and risk. We assert that the integrated approach has the following advantages:

- It is cost-effective and can provide data and results in the minimum amount of spending.

- The quality of analysis is at a high level of standard, since it goes through a series of quality assurance (QA) process.

French Telecom is one of a big European telecommunication service provider and is a major provider with iPhone $4 \mathrm{~S}$ together with Orange, Vodafone and T-Mobile. France is well-known for its creativity and there are groups of active users for using mobile applications and services. However, the economic downturn has caused more job losses in France and towns with farming and leisure focus have been affected by downturn considerably (Cavailhes et al., 1994), and the same situation applies for 2011. This makes a huge decrease in the number of iPhone users, since a number of customers have changed to cheaper mobile models with cheaper service fees, or are in the progress of doing so.

Telecommunication services in Italy are active and have major service providers offering iPhone $4 \mathrm{~S}$ services in Italy. However, Italy is one of the worse economic performers in EU and has been hit in particular by Euro zone crisis in 2011. This makes Italy in a vulnerable position and is near to a recession level, which can lose several percentages of iPhone users due to its high prices.

In regard to discussion in introduction about the relationship between the Mobile Cloud Service and, results in our previous papers (Chang et al., 2011 b; 2013 a; Chang, 2014 c, 2014 d) also demonstrate the direct relationship between the user satisfaction and the economic downturn or the business performance of the invested company. In our previous work (Chang, 2014 c; 2014 d), results support the case that the customer satisfaction is related to the economic downturn. In other words, the customer satisfaction is influenced by a country's economy. Our rationale from that data analysis is that if the country is in economic crisis and customers have either receive less pay or at the risk of losing their jobs, they feel that Mobile service may cost them more than the necessity in life such food and accommodation. Based on the observations in our previous studies and the analysis of German and Spanish data, we propose the first hypothesis:

\section{H 1. The rate of customer satisfaction in Mobile Cloud Services can reflect the recovery on economy}

The results in this section will justify whether our hypothesis can be validated. Both Heskett and Schlesinger (1994) and Hallowell (1994) demonstrate the direct positive relationship between the improved customer satisfaction and profitability. This concept is applicable to information and communication technologies including mobile phone industry and its new services (Dinh et al., 2011; Qiang et al, 2012). In other words, if there is a high customer satisfaction, profitability is expected for businesses. Additionally, Mobile Cloud is a fast-growing area that needs more attention and better strategies (Marston et al., 2011; Idongesit and Skouby, 2014). The ability to purchase 
mobile phones and its new services such as Mobile Cloud can provide good indications on the recovery on economy due to the direct impact on consumer spending and billions of Euros of revenues generated in this sector (Worldpanel ComTech, 2011; USwitch survey, 2011). This means that if many people in Country A are willing to pay for new mobile phones with its monthly bills and its new services, consumer spending tend to provide positive outcomes to the quarterly consumer spending data and quarterly GDP in its retail sales. In other words, all these contribute to the positive data in the quarterly macroeconomic measurement of Country A. Thus, the rate of customer satisfaction in Mobile Cloud can reflect the recovery on economy.

The OSM approach can ensure a high quality of analysis and a low cost spending can be achieved. This can ensure a higher return status for investors. In addition, market contests between smart phones, mobile clouds, service providers and mobile applications for Clouds have become more competitive than before and it is useful to keep track of market demands and consumer requirements so that our Cloud strategies and recommendation can be kept up-to-date.

\subsection{Data processing and analysis overview}

This section describes the computational analysis of the collected datasets and explains the interpretations from the data. The source of data is from Kantar Worldpanel ComTech (2011), a market research company, as well as Anastaya (2011), a consulting firm specializing in data analysis. The author worked in Anastaya for a period of time as a part-time consultant. A thorough data analysis approach has been adopted to ensure data analysis can be unbiased and reflect the actual risk and return status of the mobile cloud adoption. The objective of this research is to analyze the rate of satisfaction and the rate of adoption in the EU zone such as France and Italy.

Although Kantar Worldpanel ComTech has published a report on the iPhone 4S business performance in EU, it does not provide detailed statistical and computational analysis. It only offers an estimated percentage of performance downgrade and does not provide any detailed analysis. Hence, we aim to offer a more comprehensive analysis with the following objectives:

- Compute the exact extent of performance downgrade (or improvement) in EU countries. In this paper, we focus on the French data because France is a country behind EU policy with Germany. Italy is a country that has been particularly hit by economic downturn, although it still remains as a G7 nation as one of the leading developed countries in the world.

- Our previous work already analyzed the German and Spanish data (Chang, 2014 c, 2014 d). Analyzing French and Italian data is a good reflection on how top-tier EU country performed in the economic crisis.

- To provide a rationale and analysis about their performance (downgrade) based on our results. 
Datasets follow the requirements of the OSM formula (2). Each row of data contains the numerical values for the actual value, expected value and risk-control rate of the French Mobile customer satisfaction. Similar steps are undertaken for the Italian data. Each row of datasets contains the actual and expected values of measurement, and risk-control rate associated with each pair of actual and expected values. The data processing takes each row of datasets - reading all data values; putting data values into the formulas; and then perform statistical regression while using OSM.

\subsection{OSM metrics}

The use of OSM metrics is as follows.

1. The expected values included the 2010 to 2011 data taken a year before the study began. The actual values included the 2011 data, to investigate the usage of mobile cloud adoption in 2012.

2. The risk data between 2011 and 2012 was collected by Kantar Worldpanel ComTech. It was measured based on the percentage of dissatisfied users (although they were dissatisfied, they still used iPhone $4 \mathrm{~S}$ services. This was a risk-control rate - if Apple could offer better and cheaper deals, users would be happy to stay on based on their feedback) measured in major French cities: Paris, Lyon, Marseille, Toulouse, Lille and Nice.

3. In terms of the Italian data, the data collection process was identical to the point 1 and 2 above, except six Italian cities were chosen for customer satisfaction survey: Rome, Milan, Venice, Naples, Turin and Bologna.

After collecting the metrics, OSM data processing took place as described in Section 3.2. Results and analysis for French and Italian data will be presented as follows.

\subsection{OSM data analysis for French data}

This section presents results of the French data analysis and explains the interpretations of all these key statistical values. All the data is based on between January 2011 till December 2011, which provides twelve months of period of customer satisfaction measurement for iPhone $4 \mathrm{~S}$. OSM can be modeled by statistical languages, in which SAS is more suitable than other languages since it can compute more in-depth analysis (Chang et al., $2011 \mathrm{~b} ; 2011 \mathrm{c}$ ). The data is carefully calculated, examined and analyzed. Twelve months of data for this case study is sufficient to analyze its business performance, since this is a model specific approach and often Apple product performance can be determined within the first few months in the market release (Kantar Worldpanel ComTech, 2011). SAS program for OSM is coded for computation and Table 1 shows the summary of OSM key statistics. 
Table 1: OSM key statistics for French data in Mobile Cloud analysis

\begin{tabular}{|c|c|c|c|}
\hline $\begin{array}{l}\text { Beta } \\
96.12 \% \text { of risks: } \\
\text { external and } 3.88 \% \\
\text { of risks: internal }\end{array}$ & 0.7723 & $\begin{array}{l}\quad \text { Durbin-Watson }\left(4^{\text {th }} \text { order) }\right. \\
\text { Pr }>\text { DW (negative autocorrelation: } \\
\text { maximum of } 1 \text { ) } \\
\text { Positive autocorrelation (p-value) }\end{array}$ & $\begin{array}{l}1.0439 \\
0.9958 \\
0.0042 \\
\end{array}$ \\
\hline Standard Error & 0.0266 & Regress R-Square (99.99 C.I) & 0.9612 \\
\hline $\begin{array}{l}\text { Mean Square Error } \\
\text { (MSE) }\end{array}$ & 0.00769 & Regress R-Square (95 C.I) & 0.9723 \\
\hline
\end{tabular}

Further explanations are presented as follows.

- Beta is equal to 0.7723 . The medium-high value suggests the project risk is maintained at an acceptable control rate.

- Standard error is 0.0266 . The low value suggests most metrics are close to each other and the data has few extremes. There is an extremely high consistency between all metrics.

- The fourth order Durbin-Watson: It means Durbin-Watson has been regressed four times to get the most accurate values for analysis. Durbin-Watson value is 1.0439. $\mathrm{Pr}>\mathrm{DW}$ is equal to 0.9958 and is very close to 1 , showing that there is a high negative auto-correlation. Similarly, the positive p-value is 0.0042 , which indicates that the possibility of extreme cases is very small and below $0.42 \%$.

- The extremely low Mean Square Error (MSE) value suggests an excellent consistency between actual and expected return values.

- Main regression R-square is 0.9612 . It means $96.12 \%$ of the risks are from the externals such as the impacts of financial crisis that prevented users from spending more and $3.88 \%$ of the risks are from the internals such as the operations and strategies set by French telecommunication companies.

\subsection{OSM data analysis for Italian data}

All the steps are similar to sections above, except this is the analysis for Italian data. All the data is based on between January 2011 till December 2011, which provides twelve months of period of customer satisfaction measurement for iPhone 4S. Careful data analysis and examination has been applied and Table 2 shows the results.

Table 2: OSM key statistics for Italian data in Mobile Cloud analysis

\begin{tabular}{|c|c|c|c|}
\hline Beta & 0.8070 & Durbin-Watson ( $4^{\text {th }}$ order $)$ & 1.3801 \\
\hline $\begin{array}{l}58.05 \% \text { of risks: } \\
\text { external and } 41.95 \% \\
\text { of risks: internal }\end{array}$ & & $\begin{array}{l}\text { Pr }>\text { DW (negative } \\
\text { autocorrelation: maximum of } 1 \text { ) } \\
\text { Positive autocorrelation ( } \mathrm{p}- \\
\text { value) }\end{array}$ & 0.9792 \\
\hline Standard Error & 0.1117 & Regress R-Square (99.99 C.I) & 0.5805 \\
\hline $\begin{array}{l}\text { Mean Square Error } \\
\text { (MSE) }\end{array}$ & 0.15311 & Regress R-Square (95 C.I) & 0.6637 \\
\hline
\end{tabular}

Further explanations are presented as follows. 
- Beta is equal to 0.8070 . The medium-high value suggests the project risk is maintained at an acceptably controlled rate. The mobile service provider should be aware of the risk imposed by the price, service and customer satisfaction.

- Standard error is 0.1117 . The low value suggests most metrics are close to each other and the data has fewer extremes. There is a high consistency between all metrics.

- The first order Durbin-Watson: Durbin-Watson value is 1.3801. Pr $>$ DW is equal to 0.9792 and is very close to 1 , showing that there is a high negative autocorrelation. Similarly, the positive p-value is 0.0208 , which indicates that the possibility outside the $95 \%$ confidence limit (0.05) is very low and unlikely.

- The low Mean Square Error (MSE) value suggests an excellent consistency between actual and expected return values.

- Main regression R-square is 0.5805 . It means $58.05 \%$ of the risks are from the externals such as the impacts of financial crisis that prevented users from spending more. $41.95 \%$ of the risks are from the internals such as the prices, the quality of service, operations and strategies set by telecommunication companies, which should consider lowering prices or offering incentives for existing customers.

\section{3D Visualization: Further analysis to support French and Italian case studies}

OSM supports the development of 3D Visualization. The benefit is to consolidate interpretations from data analysis. Statistical analysis can only explain what each key OSM output means. 3D Visualization can provide an overview about the project by presenting the three key metrics: actual return value, expected return value and riskcontrolled rate head-to-head. This also provides stakeholders a platform to double check with existing analysis, so that no other data analysis and interpretations can be missed. The shape presented by the 3D Visualization can consolidate interpretation of data analysis as demonstrated in our previous work (Chang et al., 2011 b, 2011 c; Chang, 2014 c; 2014 d). If there are spikes or bumps, it means that the project may experience a volatile period that can prevent the progress of the project, or delivery of the service to the users/customers. The most ideal situations can be:

- An overall trend of upward movement: This means that the project is on the way up, with increasing the expected return values and actual return values over the period of the project/service.

- There are few spikes and bumps: It means that the project is not having any volatile period or factors that contribute to the development of uncontrolled risk.

The focus of this chapter is to demonstrate that 3D Visualization can help interpret further data analysis, rather than the computational

\subsection{OSM data analysis for French data}

Figure 1 shows Visualization for customer satisfaction in using iPhone 4S Mobile Cloud services in France between January and December 2011. The x-axis shows the 
actual rate of customer satisfaction is between -7.5 to $-9.5 \%$, and the y-axis shows the expected rate of customer satisfaction is between -6.0 to $-7.5 \%$ and $\mathrm{z}$-axis presents riskcontrol rate is between 1.2 and $1.8 \%$. Although the decline was expected before the survey process and data collection, the actual rate of declined customer satisfaction is higher than expected values. Possible reasons may include that the customers felt the prices were high, or the services were not improving, and issues in their previous iPhone and Mobile services left unresolved in their new contracts. The French data has only minor spikes and bumps, which means that the overall service between January and December 2011 was still considered a manageable experience for Mobile service providers. Similar to German data analysis (Chang, 2014 c; 2014 d), actual iPhone usage is lower than the expected rate. This may imply a large number of users did not continue with iPhone services and switch to cheaper models and services due to its higher prices and impact of downturn. 3D Visualization helps businesses interpret the likely causes for their downgrade in their business targets.

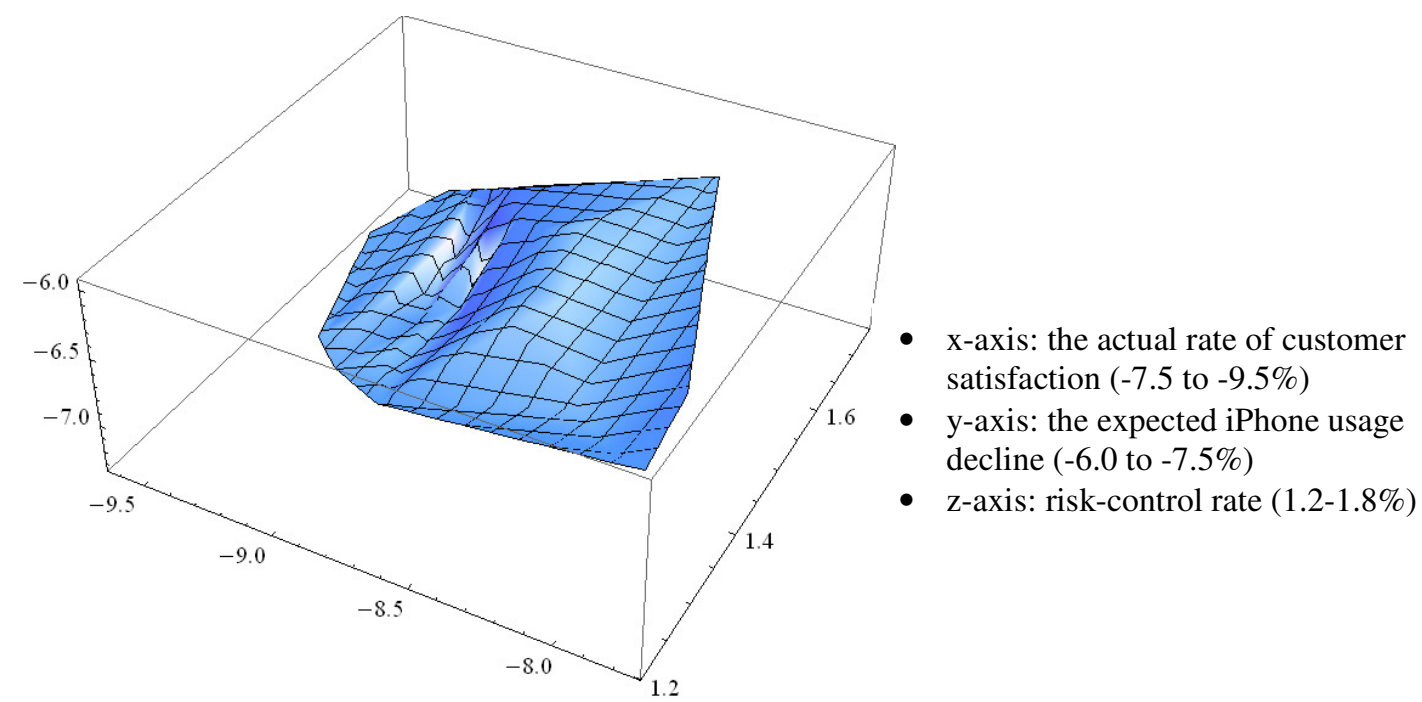

Figure 1: Visualization for customer satisfaction in using iPhone 4S Mobile Cloud services in France between January and December 2011

\subsection{OSM data analysis for Italian data}

Figure 2 shows Visualization for customer satisfaction in using iPhone 4S Mobile Cloud services in Italy between January and December 2011. The X-axis shows the actual rate of customer satisfaction is between -4.0 to $-6.0 \%$, and the $y$-axis shows the expected rate of customer satisfaction is between -3.0 to $-5.0 \%$ and z-axis presents risk-control rate is between 1.0 and $1.8 \%$. Although the decline was expected before the survey process and data collection, the actual rate of declined customer satisfaction is higher than expected values. However, the difference between French and Italian data is that Rsquared in Italian data is much lower, with $58.05 \%$ for the external risk and $41.95 \%$ for the internal risk. Interestingly, numerous Italian feedback comments suggested that customers criticized the former prime minister's policy for telecommunication industry (that he was the tycoon) and regarded this risk as internal rather external. This may also explain why there are more bumps and one major spike seen in Visualization suggesting 
the Mobile Cloud service might experience a turbulent period. Additionally, other possible reasons are similar to the French data: high prices, unimproved services and no value for money. 3D Visualization again can consolidate interpretation of data analysis in the Italian data.

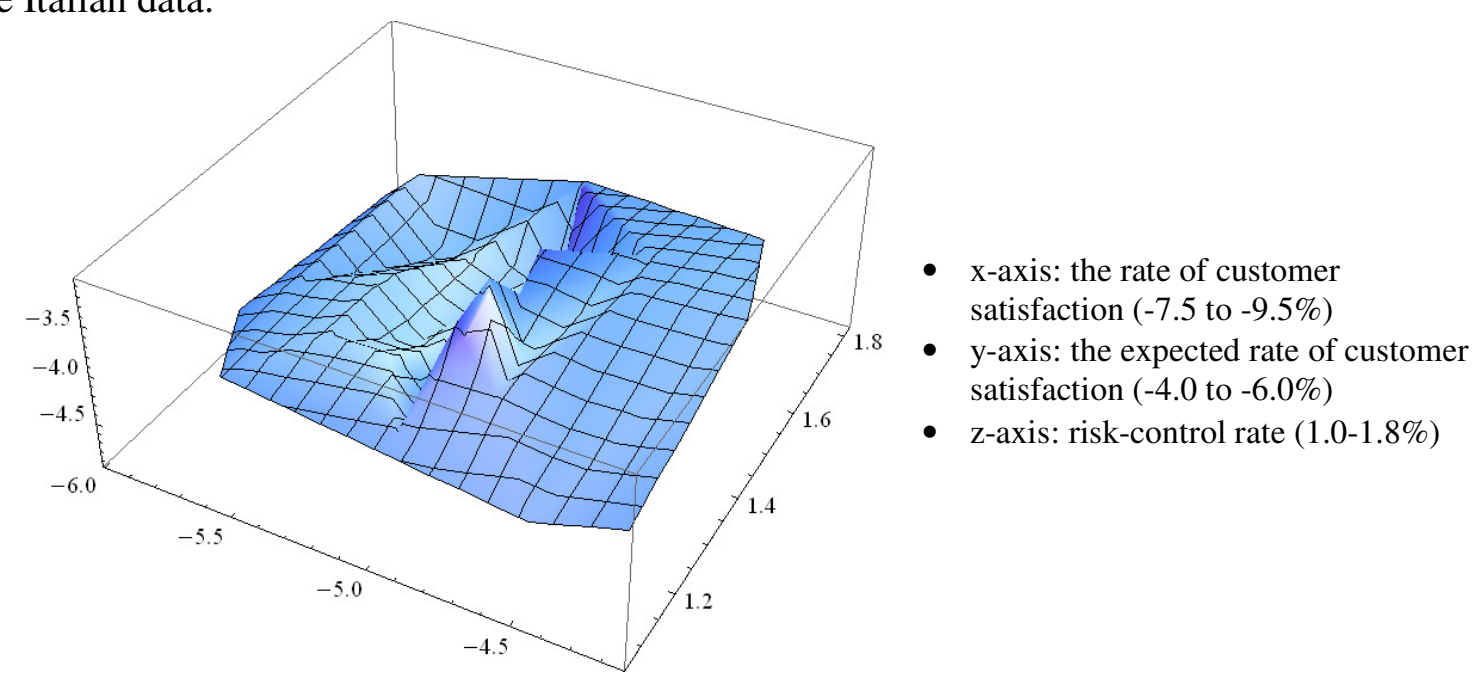

Figure 2: Visualization for customer satisfaction in using iPhone 4S Mobile Cloud services in Italy between January and December 2011

\subsection{Summary of 3D Visualization}

The OSM metrics include actual return values, expected return values and riskcontrolled rate, which can be computed as 3D Visualization. The aim is to help interpret the complex analysis into a format that the stakeholders and reviewers without statistical or computing backgrounds can understand. The use of visualization is crucial to the development of the organizational business intelligence strategy that can blend their business processes with the use of Cloud Computing services (Loshin, 2012).

\subsection{Testing of our hypothesis}

Results of French and Italian data fully support our hypothesis. Since both countries had economic crisis, it influenced the way that people perceived about spending more money in their Mobile Cloud services. The OSM outputs and interpretations show that the decline of the customer satisfaction is due to the higher expenses, services not improved and not value for money. Thus, some customers left for cheaper services. However, more data analysis on more smart phone models and countries will help to fully validate our first hypothesis.

\section{Discussion}

This section presents two topics for discussion. The first topic is the general discussions about the OSM. The second topic is the general discussion about the Mobile Cloud services and competitions with other vendors, as well as future direction that can 
influence the Mobile Cloud service. The third topic is the comparison with other similar models.

\subsection{General discussions about OSM}

This section presents the overall discussions with OSM and the comparison with the original model, CAPM. While CAPM is not designed to handle huge datasets and is not designed for analysis of system adoption such as Cloud Computing, OSM has an improved methodology and formula. OSM can compute thousands of datasets at once and is designed for Computing (including Cloud Computing) rather than being a generic model for risk and return. While identifying and collecting metrics for actual return values, expected return values, risk-control rates, OSM can calculate key values including beta, standard error and Durbin-Watson (with negative autocorrelation) to interpret the collected datasets. A project with good Cloud adoption including Mobile Cloud should have the followings:

- Low beta: the project has lower uncontrolled risk.

- Low standard error: Results of collected datasets have high consistency between one another.

- Durbin-Watson: The value is above 1, and negative autocorrelation test is as close as to 1 as possible. The positive autocorrelation is equivalent to the p-value, which should be 0.05 and below, to correspond that all datapoints are within the $95 \%$ confidence interval.

- R-squared values can identify the proportions and sources of beta risks. It should be above 0.5 and below 1 .

- Mean Squared values and positive p-values should have low values to support accuracy of OSM analysis.

\subsection{OSM for Mobile Cloud survey research and future direction in Mobile Cloud}

OSM is the only model developed in academia that has numerous case studies that can analyze the risk and return status for projects with Cloud adoption, including Mobile Cloud Service. Our previous work has presented the case studies for Vodafone/Apple Mobile Cloud strategies in 2009 and iPhone 4S customer satisfaction in Germany between January and December 2011. This paper presents two case studies of analyzing French and Italian customer satisfaction data between January and December 2011.

Mobile Cloud is a highly competitive area that services need to be constantly improved and prices should be reasonably adjusted (Marston et al., 2011; Dinh et al., 2011; Worldpanel ComTech, 2011; USwitch survey, 2011; Dinh et al., 2011; Qiang et al, 2012; Idongesit and Skouby, 2014). There are other mobile service providers offering Samsung, HTC, Sony and Nokia/Windows services that require further analysis. Future direction will focus on measuring and analyzing customer satisfaction for the following areas:

- Analysis of iPhone 4S for United Kingdom in 2011

- Analysis of iPhone 5 and iPhone for United Kingdom in 2012 and 2013 respectively. 
- Analysis of iPhone 5 and iPhone for Germany, France and Italy in 2012 and 2013

- Analysis of Samsung high-end phones for United Kingdom, Germany, France and Italy in 2012 and 2013 respectively.

- Analysis of HTC, Sony and Nokia/Windows Mobile Cloud services for United Kingdom, Germany, France and Italy in 2012 and 2013 respectively.

We will work closely with consultancy firms that analyze the rate of customer satisfaction for Mobile Cloud services. Hypotheses will be set based on the observation of results and analysis. We will have more data and their interpretations to validate our first hypothesis: "H1. The rate of customer satisfaction in Mobile Cloud Services can reflect the recovery on economy" and we will use more varieties of phones and their services to validate. Currently, results in our analysis and interpretations in Section 4 and 5 support this hypothesis.

\subsection{Comparisons with similar models}

This section is focused on comparison between OSM, CAPM and similar models, particularly the three models mentioned in Section 3.4. The reason to include them is because they proposed similar method years ago. We assert in Section 3.4 that all proposed frameworks or models should have the support from real-life case studies or demonstrations or both to make them justifiable for organizations for adoption. The criteria for comparison are explained as follows:

1. Support form real case studies and demonstrations: it was described earlier.

2. Detail and clarity of using the model/framework: the proposed method should describe details about how to adopt and how to use. These should include what types of metrics, details in the data processing, what are the inputs and outputs and interpretation of results.

3. Continuous contributions to the research community: This is a different from point one. After the publication of their first or first few papers establishing their model/framework, the proposers should have continuous publication and regularly contribute new findings and improvements to their proposed method. Improvements should include any other areas such as the performance in data processing, improved technique, update from the first or first few papers and so forth.

Comparing OSM with the original models proposed by Weinhardt et al (2009), Klem et al (2009) and Sultant (2010), OSM is the model that has continuous contributions to the research community by publishing the improved technical performance, data processing, analysis of results. More importantly, there is a strong support from case studies by Vodafone/Apple, SAP, Universities of Southampton, Greenwich and Oxford, Leeds Metropolitan University, King's College London, and Guy's and St Thomas' NHS Trusts (GSTT), who have used Cloud Computing adoption and key metrics developed and recommended by OSM. This explains why Cloud Computing adoption should have strong support from real-life case studies and demonstrations. Other than OSM, Buyya et 
al (2009) have continuous contribution to the development of Cloud Computing projects and services.

Table 3: Comparisons between OSM and similar methods

\begin{tabular}{|c|c|c|c|}
\hline $\begin{array}{l}\text { Models and } \\
\text { criteria }\end{array}$ & $\begin{array}{llr}\text { Support } & \text { from } & \text { real-life } \\
\text { case } & \text { studies } & \text { and } \\
\text { demonstrations } & \end{array}$ & $\begin{array}{l}\text { Detail and clarity of } \\
\text { using the model or } \\
\text { framework }\end{array}$ & $\begin{array}{l}\text { Continuous } \\
\text { contributions to the } \\
\text { research community }\end{array}$ \\
\hline $\begin{array}{l}\text { Weinhardt et } \\
\text { al (2009) }\end{array}$ & $\begin{array}{l}\text { The proposed method is } \\
\text { a conceptual idea. It } \\
\text { offers a generic } \\
\text { recommendation. There } \\
\text { is no any case study or } \\
\text { demonstration based on } \\
\text { this. }\end{array}$ & $\begin{array}{l}\text { The proposed method } \\
\text { is a conceptual idea } \\
\text { and there is no detail } \\
\text { about how to use and } \\
\text { replicate their work. }\end{array}$ & $\begin{array}{l}\text { They published three } \\
\text { papers with similar } \\
\text { content in } 2009 \text { and } \\
2010 \text {. There is no } \\
\text { any update since } \\
2010 \text {. }\end{array}$ \\
\hline $\begin{array}{l}\text { Klem et al } \\
(2009)\end{array}$ & $\begin{array}{l}\text { The proposed method is } \\
\text { a conceptual idea. It } \\
\text { offers a generic } \\
\text { recommendation. There } \\
\text { is no any case study or } \\
\text { demonstration based on } \\
\text { this. }\end{array}$ & $\begin{array}{l}\text { The proposed method } \\
\text { is a conceptual idea } \\
\text { and there is no detail } \\
\text { about how to use and } \\
\text { replicate their work. }\end{array}$ & $\begin{array}{l}\text { They published three } \\
\text { papers with similar } \\
\text { content in } 2009 \text { and } \\
2009 \text {. There is no } \\
\text { any update since } \\
2009 \text {. }\end{array}$ \\
\hline $\begin{array}{l}\text { Sultant } \\
(2010 ; 2014)\end{array}$ & $\begin{array}{l}\text { A case study was } \\
\text { published in } 2013 \text { since } \\
\text { his paper in } 2010 \\
\text { (Sultan, 2014). Even so, } \\
\text { that paper is about the } \\
\text { investigation about how } \\
\text { a NHS hospital uses } \\
\text { Cloud Computing. It is } \\
\text { not how the NHS } \\
\text { hospital uses his model } \\
\text { and makes positive } \\
\text { impact. }\end{array}$ & $\begin{array}{l}\text { The proposed method } \\
\text { is a conceptual idea } \\
\text { and discussions based } \\
\text { on other people work } \\
\text { before establishing his } \\
\text { recommendation. } \\
\text { There is no detail } \\
\text { about how to use his } \\
\text { model since they are } \\
\text { all qualitative } \\
\text { descriptions. }\end{array}$ & $\begin{array}{l}\text { He published papers } \\
\text { since } 2010 \text {. Later on, } \\
\text { there is an update in } \\
\text { the case study in } \\
\text { April } 2014 \text {. }\end{array}$ \\
\hline $\begin{array}{l}\text { OSM (Chang } \\
\text { et al. } 2011 \text { b; } \\
2011 \text { c; } 2012 \\
\text { a; Chang } \\
2013 \text { a) }\end{array}$ & $\begin{array}{l}\text { OSM has case studies } \\
\text { for Vodafone/Apple, } \\
\text { SAP, Universities of } \\
\text { Southampton, } \\
\text { Greenwich and Oxford, } \\
\text { Leeds Metropolitan } \\
\text { University, King's } \\
\text { College London, and } \\
\text { Guy's and St Thomas' } \\
\text { NHS Trusts. }\end{array}$ & $\begin{array}{l}\text { Details have } \text { been } \\
\text { presented. } \\
\text { include } \\
\text { demonstrations } \\
\begin{array}{l}\text { healthcare, finance, } \\
\text { education } \\
\text { emerging areas. and }\end{array}\end{array}$ & $\begin{array}{l}\text { Papers have been } \\
\text { published to discuss } \\
\text { the results, data } \\
\text { processing, } \\
\text { interpretation of } \\
\text { analysis for } \\
\text { continuous update } \\
\text { and improvement. }\end{array}$ \\
\hline
\end{tabular}




\section{Conclusion and Future work}

Cloud computing is an emerging technology which promises to change the way organizations view their computing systems, as well as how consumers use and rate Cloud services. This includes Mobile Cloud industry, which is a competitive area. This paper presents the French and Italian data about the user satisfaction rate of using iPhone 4S Mobile Cloud services. French and Italian data have good consistencies between all the values in the datasets and have medium-high uncontrolled risk. Figures in 3D Visualization can show whether there are spikes and bumps that need more attention to investigate. This information is useful to the stakeholders to understand the status of risk and return. We also explain the use of OSM in the data collection and analysis, and results computed by OSM. Results presented in this paper and our previous paper support the hypothesis that the rate of customer satisfaction in Mobile Cloud Services can reflect the recovery on economy. We also compare OSM with other similar approaches. OSM and approaches proposed by Buyya et al (2009) can demonstrate continuous contributions to the research community. We also explain how to use OSM to analyze results and the results of good projects. Our future work includes the data analysis of other smart phone and their Cloud services in the United Kingdom, Germany, France, Italy and Spain, so that they can consolidate our hypotheses about the rate of customer satisfaction in Mobile Cloud Services in regard to the economic recovery in European countries.

\section{References}

Anastaya, data analysis for mobile industry, white paper, 2011.

Barry, D. K. (2012). Web Services, Service-oriented Architectures, and Cloud Computing: The Savvy Manager's Guide. Newnes.

Buyya, R., Yeo, C. S., Venugopal, S., Broberg, J., \& Brandic, I. (2009). Cloud computing and emerging IT platforms: Vision, hype, and reality for delivering computing as the 5th utility. Future Generation computer systems, 25(6), 599-616.

Cavailhes, J., Dessendre, C. Goffette-Nagot, F., Schmitt, B. (1994) Change in the French countryside: some analytical propositions. European Review of Agricultural Economics, 21 (3-4), pp. 429-449.

Carr, P., and Madan, D. (1999). Option valuation using the fast Fourier transform.Journal of computational finance, 2(4), 61-73.

Chang, V. (2013) A proposed model to analyse risk and return for a large computing system adoption. University of Southampton, Physical Science and Engineering, Doctoral Thesis, 288pp.

Chang, V. (2014 a) Introduction to the Risk Visualization as a Service. In, The first international workshop on Emerging Software as a Service and Analytics, Barcelona, ES, 03 - 05 Apr 2014.

Chang, V. (2014 b) An Introductory Approach to Risk Visualization as a Service. Open Journal of Cloud Computing, 1, (1), 1-9. 
Chang, V., (2014 c) The Big Data Analysis for measuring popularity in the Mobile Cloud. In, The first international workshop on Emerging Software as a Service and Analytics, ESaaSA 2014, Barcelona, Spain, 3 - 5 Apr.

Chang, V. (2014 d) Measuring and analyzing German and Spanish customer satisfaction of using the iPhone 4S Mobile Cloud service. Open Journal of Cloud Computing, 1, (1), 19-26.

Chang, V., Li, C. S., De Roure, D., Wills, G., Walters, R., \& Chee, C. (2011 a). The financial clouds review. International Journal of Cloud Applications and Computing, 1(2), 41-63.

Chang, V., De Roure, D., Walters, R. J. and Wills, G., Barry, T., (2011 b) Organisational Sustainability Modelling for Return on Investment: Case Studies presented by a National Health Service (NHS) Trust UK. Journal of Computing and Information Technology, 19, (3)

Chang, V., De Roure, D., Wills, G. and Walters, R. (2011 c) Case Studies and Organisational Sustainability Modelling presented by Cloud Computing Business Framework. International Journal of Web Services Research, 8, (3), 26-53.

Chang, V., Walters, R. J. and Wills, Gary (2013 a) Cloud Storage and Bioinformatics in a private cloud deployment: Lessons for Data Intensive research. In Cloud Computing and Service Science, Springer Lecture Notes Series, Springer Book.

Chang, V., Walters, R. J. and Wills, G. (2013 b) The development that leads to the Cloud Computing Business Framework. International Journal of Information Management, June, 33, (3), 524-538.

Dinh, H. T., Lee, C., Niyato, D., \& Wang, P. (2011). A survey of mobile cloud computing: architecture, applications, and approaches. Wireless communications and mobile computing.

Durbin, J., Watson, G.S (1950) Testing for Serial Correlation in Least Squares Regression: I, Biometrika, 37, pp 409-428

Eberlein, E., and Keller, U. (1995). Hyperbolic distributions in finance. Bernoulli,1(3), 281-299.

Ganti, R. K., Ye, F., and Lei, H.: Mobile crowdsensing: Current state and future challenges. Communications Magazine, IEEE, 49(11), 32-39, (2011).

Gentzoglanis, A. EVA and the Cloud: An Integrated Approach to Modelling of Cloud Computing, International Journal of Modellling and Optimization, 1 (2011) 322-327

Hallowell, R. (1996). The relationships of customer satisfaction, customer loyalty, and profitability: an empirical study. International journal of service industry management, 7(4), 2742.

Heskett, J. L., \& Schlesinger, L. A. (1994). Putting the service-profit chain to work. Harvard business review, 72(2), 164-174.

Hull, J.C. Options, Futures, and Other Derivatives, Seventh Edition ed., Pearson, Prentice Hall, 2009.

Idongesit, W., \& Skouby, K. E. (Eds.). (2014). The African Mobile Story. River Publishers. 
Jampani, R., Xu, F., Wu, M., Perez, L. L., Jermaine, C., \& Haas, P. J. (2008, June). MCDB: a monte carlo approach to managing uncertain data. In Proceedings of the 2008 ACM SIGMOD international conference on Management of data (pp. 687-700). ACM.

Kantar Worldpanel ComTech: Kantar Worldpanel ComTech Global Consumer, White paper and VIP report, December, (2011).

Klems, M., Nimis, J., \& Tai, S. (2009). Do clouds compute? a framework for estimating the value of cloud computing. In Designing E-Business Systems. Markets, Services, and Networks (pp. 110-123). Springer Berlin Heidelberg.

Lee, C.F., Lee, A.C. , Lee, J., Handbook of Quantitative Finance and Risk Management, in, Springer, 2010.

Longstaff, F. A., \& Schwartz, E. S. (2001). Valuing American options by simulation: A simple least-squares approach. Review of Financial studies,14(1), 113-147.

Loshin, D. (2012). Business intelligence: the savvy manager's guide. Newnes.

Marston, S., Li, Z., Bandyopadhyay, S., Zhang, J., \& Ghalsasi, A. (2011). Cloud computing-The business perspective. Decision Support Systems, 51(1), 176-189.

Rimal, B. P., Jukan, A., Katsaros, D., and Goeleven, Y.: Architectural requirements for cloud computing systems: an enterprise cloud approach. Journal of Grid Computing, 9(1), 3-26, (2011).

Rochwerger, B., Breitgand, D., Levy, E., Galis, A., Nagin, K., Llorente, I. M and Galan, F. (2009). The reservoir model and architecture for open federated cloud computing. IBM Journal of Research and Development, 53(4), 4-1.

Qiang, C. Z., Yamamichi, M., Hausman, V., Altman, D., \& Unit, I. S. (2011). Mobile applications for the health sector. Washington: World Bank.

Sharma, B., Thulasiram, R. K., Thulasiraman, P., Garg, S. K., Buyya, R., (2012). Pricing cloud compute commodities: a novel financial economic model. In Proceedings of the 2012 12th IEEE/ACM International Symposium on Cluster, Cloud and Grid Computing (ccgrid 2012) (pp. 451-457), May, IEEE Computer Society.

Sharpe, W. F. (1990), Capital Asset Prices with and without Negative Holdings, Nobel-Prize Economics Lecture, pp 312-332, Dec 7.

Sultan, N. (2010). Cloud computing for education: A new dawn?. International Journal of Information Management, 30(2), 109-116.

Sultan, N. (2014). Making use of cloud computing for healthcare provision: Opportunities and challenges. International Journal of Information Management, 34(2), 177-184

Teunis, P. F. M., \& Havelaar, A. H. (2000). The Beta Poisson Dose - Response Model Is Not a Single - Hit Model. Risk Analysis, 20(4), 513-520.. 
USwitch survey, USwitch's Guide to Mobile Phones, September 2011.

Weinhardt, C., Anandasivam, D. I. W. A., Blau, B., Borissov, D. I. N., Meinl, D. M. T., Michalk, D. I. W. W., \& Stößer, J. (2009). Cloud computing-a classification, business models, and research directions. Business \& Information Systems Engineering, 1(5), 391-399. 